\title{
Um Jardim em Floresta
}

\author{
Claudia Tavares ${ }^{1}$
}

Resumo: A tese articula arte e natureza sob a égide do elemento água e do conceito de jardim. É uma pesquisa que se inicia dentro de um ateliê no Rio de Janeiro e planta um jardim no sertão de Pernambuco. A hipótese central é de que a natureza assume o lugar de parceria em trabalhos de arte contemporânea.

Palavras chave: água, ateliê-mina, jardim, natureza

\section{A garden in Floresta}

\begin{abstract}
The thesis articulates art and nature under the aegis of the water element and the concept of garden. It is a research that begins inside a studio in Rio de Janeiro and plants a garden in the dry backlands of Pernambuco. A central hypothesis is that nature acts as a partner in relation to works of contemporary art.
\end{abstract}

Key-words: water, studio-mine, garden, nature

\footnotetext{
${ }^{1}$ Claudia Tavares é Doutora em Processos Artísticos Contemporâneos pelo Instituto de Artes UERJ, sendo contemplada com a Bolsa Faperj Nota 102016 e Bolsa Capes PDSE 2017. É Mestra em Artes pela Goldsmiths College, Londres e em Linguagens Visuais pela Escola de Belas Artes, UFRJ.

0 trabalho artístico se apoia principalmente na linguagem da fotografia e do vídeo, com pensamento instalativo em convívio com objetos, desenhos e cadernos de artista.

Suas exposições individuais são "Light Boxes", 2001, 291 Gallery, Londres, "entre nuvem e vento", 2007, Galeria do Ateliê, Rio de Janeiro, "Nós", 2011, Espaço Sérgio Porto, Rio de Janeiro, "Branco Preto", 2012, Galeria Tempo, Rio de Janeiro, "Vestida de infância", 2015, Galeria do Ateliê, Rio de Janeiro. Ganhou 3o prêmio na 9o Bienal Nacional de Santos 2004, o Edital de Ocupação FCS 2018 e foi selecionada para o programa de residência artística Labverde 2018. Expôs na Casa França Brasil, Galeria Portinari, Rio de Janeiro e Galeria Cozinha, Porto, Portugal. Participa esse ano da Bienal de Cerveira, Vila Nova de Cerveira, Portugal e Casa Museu Abel Salazar, Porto, Portugal.

Um Jardim em Floresta, seu novo trabalho, que dá origem a sua tese, foi exposto na Galeria Mari'Stella Tristão, Palácio das Artes, BH entre Abril e Julho de 2018, no Paço Imperial, Rio de Janeiro, entre Dezembro de 2018 a Fevereiro de 2019 e na Casa de Eva, Campinas entre Agosto e Outubro de 2019.
} 
Introdução

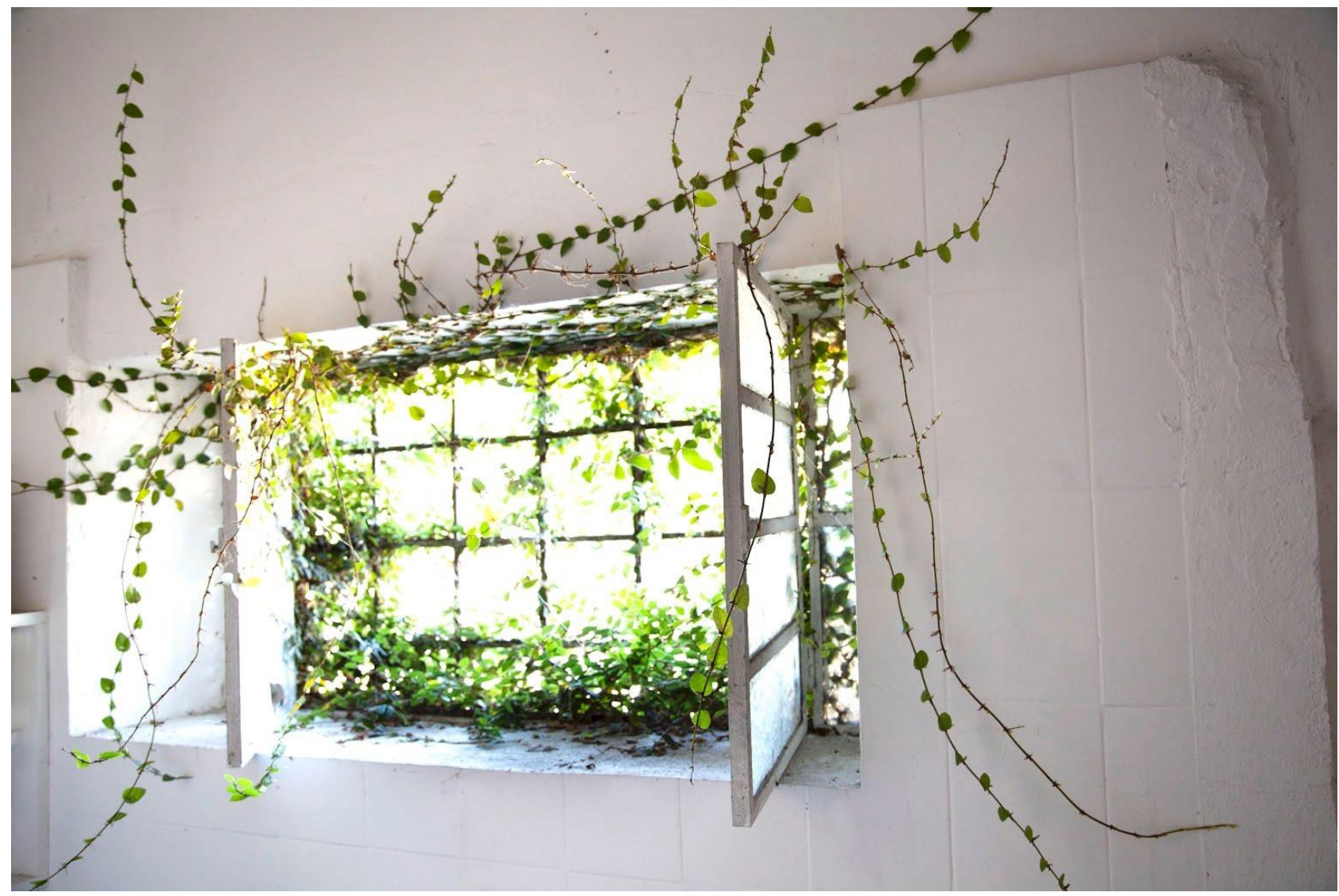

Claudia Tavares, Um jardim em Floresta, fotografia, 2014/2018

"Umidade é água escondida."

Por mais de dois anos aluguei um espaço que funcionou como ateliê. Fica no bairro de Laranjeiras, na cidade do Rio de Janeiro. A entrada é por uma porta amarela que abre diretamente para a rua. Lá dentro, um ambiente extraordinariamente úmido: um porão de uma casa construída na encosta de uma montanha rochosa. A umidade brota do chão, do teto e das paredes. Sua presença invisível desenha mapas transitórios, esgarça emboço, revela vestígios de sua passagem.

Dois desumidificadores, que transformam a umidade do ar em água, passaram a fazer parte do mobiliário do ateliê. Ambos ficavam ligados ininterruptamente. A água acumulada pelos aparelhos em seus reservatórios de plástico se esvaia quando 
despejada pela pia. Me dou conta que naquele espaço-porão existia uma espécie de mina de água. 0 meu ateliê era um ateliê-mina, lugar de nascente, fonte de riqueza.

Cotidianamente vertia a água recolhida e pensava na seca que impede a proliferação do verde e da vida no sertão brasileiro. Há um lugarejo que conheci há alguns anos atrás que reúne cerca de 80 casas e fica bem dentro do sertão de Pernambuco. É, curiosamente, chamado Floresta. Em Floresta, assim como em vários outros lugarejos ao redor, não chovia havia três anos, enquanto no meu ateliê, chovia sem parar. Entre Rio e Floresta existem dois mil e cem quilômetros de distância.

Foi no gesto diário de recolher essa umidade tornada água que surge a vontade de umedecer, mesmo que momentaneamente, o sertão seco.

Recolhia a água dos desumidificadores e a acondicionava em garrafas. Por meio delas organizava a riqueza do meu ateliê-mina. As garrafas usadas eram todas de vidro, dos mais variados tamanhos, formatos e cores. E matutava: o que fazer com toda essa água? Levá-las ao sertão era minha ideia desde o início. Pensava em estabelecer uma rota de água, uma espécie de rio voador entre Rio e Floresta. Encomendei caixas de madeira para acomodá-las na viagem. Embalei com plástico bolha uma a uma das cerca de 180 garrafas que foram então acondicionadas em 5 caixas de madeira.

Em janeiro de 2016, todas as caixas partiram de caminhão com destino ao sertão. Eu parti também. Tinha decidido que iria construir um jardim para regá-lo com a água engarrafada.

A viagem por terra entre Petrolina e Floresta desvela uma amplitude árida, de umbuzeiros, favelas e mandacarus, aparentemente sem verde e sem vida. São quilômetros de terra batida e muita poeira levantada pelos carros que cruzam. Viajei por alguns dias pelas cidadezinhas em torno de Floresta. Nuvens de chuva circulavam ao longe. Pelas estradas e ruas, ia mapeando casas que tivessem jardins. Onde as encontrava, parava e contava meu plano de construir um jardim em Floresta. Os donos dos jardins, apesar de um pouco desconfiados, me presentearam com mudas e vasos de plantas. Recolhi durante esse período o equivalente a seis 
caixas de mudas e alguns vasos de plantas. Voltei a Floresta com um carrinho carregado de verde e de afeto.

Pedi ajuda a um vaqueiro local para construir o jardim. Fizemos uma cerca `a moda sertaneja, para o proteger dos bodes, cabras, cavalos, jegues, vacas e bois, que andam à solta em busca de qualquer folhagem verde e fresca ao alcance de suas mordidas famintas. Cerca levantada, terra arada, era hora de plantar as mudas e finalmente regá-las com a água engarrafada.

Poucos dias depois, a chuva que andava circulando na redondeza chegou e choveu no jardim. Choveu o que não chovia havia muitos anos. Choveu de encher açude, de brotar relva, de formar poças de lama na estrada, de brotar as folhas adormecidas dos umbuzeiros, de reunir sapos em uma sinfonia noturna, de pingar goteira dentro de casa. Choveu. Uma chuva cheia, morna, barulhenta"i.

É a partir de Um Jardim em Floresta que esta tese se desenha. Foi na feitura do trabalho, em suas muitas dobras e no decorrer do curso de doutorado que surgiram questões que me proponho a discutir aqui. Trabalho e tese se tecendo juntos, se atravessando e se contaminando. Trabalho como sustento da tese. Tese como evaporação do trabalho. Um Jardim em Floresta aparece aqui como norteador de outros desejos, como gatilho que implica na produção de novos trabalhos e, também, na vontade de dialogar com outros artistas. A ideia é amplificar o trabalho em tese, sem limitá-lo ao território particular de sua ação. Ele se faz presente na escrita em muitos momentos, mas me proponho a escrever, pensar e pesquisar a partir dele buscando encontrar uma maior amplitude de horizonte. Penso a partir dele, e não apenas sobre ele.

Quero seguir as raízes do jardim. Pensar em questões que por ele fui levada. Como a natureza afeta a arte na contemporaneidade? Como a relação entre arte e natureza se dá num momento de profundas crises evidentes no mundo de hoje, olhando especialmente para a crise ecológica? Estas questões serão o fio condutor do pensamento desta tese. Para isso, mergulho em visões sobre a relação homem e natureza, vista e pensada antes, agora e no entrecruzamento dos tempos. Milton 
Santos, Michel Serres e Félix Guatarri são os principais pensadores que me iluminam nessa discussão. Não são teóricos da arte nem tampouco historiadores da arte. São pensadores da geografia, da ciência e da filosofia. Na ciência da geografia e da ecologia encontro autores que pensam o mundo contemporâneo pela relação entre natureza e humanidade e resolvo estabelecer um diálogo com eles. Giorgio Agamben, Roland Barthes, Jaques Rancière, Anne Cauquelin e Jean-Luc Nancy também são preciosas fontes de consulta, embora, talvez, em menor escala, porém não em menor importância. Da arte vem os artistas, com seus trabalhos, suas falas e minha enorme admiração. Giuseppe Penoni, Nelson Félix, Brígida Baltar, João Modé, Olafur Eliasson, Francis Alÿs, Cildo Meireles, Sara Ramo, Martha Jourdan, Eduardo Coimbra, Rodrigo Braga. Todos eles intercessores na minha produção. Cada um como um canteiro de um imenso jardim, com suas poéticas e particularidades.

A escrita se dá ora em forma de relato, que domina o primeiro capítulo e pontua também os seguintes, em observações sobre trabalhos dos artistas citados acima. As discussões de conceitos de determinados autores entremeiam e consolidam o pensamento. 0 processo da escrita se assemelha ao ato fotográfico. Vê, captura, armazena e processa. 0 pensamento vai colecionando instantes para depois criar diálogos na edição, numa lógica da gota à tempestade. Os títulos e subtítulos também seguem essa lógica, abrem caminhos associados dentro das duas principais matérias a serem pesquisadas: água e jardim. É dividida em três capítulos. O primeiro é dedicado ao relato do processo de Um jardim em Floresta, que julgo necessário para o desenvolvimento da escrita e melhor entendimento da proposta teórica. Dei-lhe o nome de $O$ relato da Umidade. A água é o principal elemento constituinte do planeta e do nosso corpo, fundamental para a manutenção da vida no planeta. $O$ universo de água intitula o segundo capítulo. 0 jardim sem canteiros é como chamei o terceiro capítulo dessa tese. A lógica é caminhar das definições de jardim até chegar à imensidão de uma floresta.

A constatação de uma crise ecológica planetária só pode ser revertida, segundo Félix Guattari se a subjetividade, as relações humanas e as relações com a natureza forem repensadas para reformar a concepção do ser humano sobre si mesmo, perante a 
coletividade e sobre este planeta. Refletir sobre o viés ecológico é inevitável, a humanidade atravessa esse momento de conscientização da mudança climática que afeta o funcionamento do mundo como um todo. No entanto, Um jardim em Floresta não é um trabalho de denúncia da falta d'água no sertão. Aos artistas pode ser, talvez, atribuída a partilha do sensível, como propõe Jacques Rancière, que diz "uma partilha do sensível fixa portanto, ao mesmo tempo, um comum partilhado e partes exclusivas"ii. Partilhar é dividir mas também compartilhar. Enalteço aqui a posição das práticas artísticas que apontam para as partes exclusivas (suas posições estético-políticas no mundo) de um comum partilhado (a natureza), sob a égide da parceria entre arte e natureza. Aposto na junção das falas de artistas, suas obras e conceitos teóricos e teço a escrita com essas linhas.

Opto pelo termo natureza enquanto matéria de convívio e troca, partindo de Augustin Berque que a define como factual e sensível, física e fenomenal, constituinte do homem e do seu entorno. Celebro a proposta de Michel Serres de estabelecer com ela um contrato natural, onde ambas as partes sejam parceiras e co-autoras nos trabalhos de arte e na vida. Citando Serres, "Na verdade, a Terra falanos em termos de forças, de ligações e de interações, e isso basta para celebrar um contrato. Cada um dos parceiros em simbiose deve, por direito, a sua vida ao outro, sob pena de morte"iii. Conhecer a linguagem da natureza, do seu tempo, reconhecer sua fala, vivenciar seus fenômenos, respeitar seus ciclos e estabelecer assim a arte como mais um potencial dispositivo mediador de troca e convívio entre nós, seres humanos e a terra, natureza. Acredito nessa mediação da arte como amplo campo de provocação de ideias, sentidos e sensações.

O capítulo 1 é dedicado ao relato do processo do trabalho Um jardim em Floresta, que julgo necessário para o desenvolvimento da escrita e melhor entendimento da proposta teórica. Dei-lhe o nome de $O$ relato da Umidade. Neblina, primeiro subtítulo, é a condensação de água evaporada que forma névoa na altura do solo, uma metáfora para falar da percepção de que o trabalho estava se constituindo no ambiente do ateliê, porém ainda sem muita clareza de como e do que viria a ser. Existia a percepção do excesso de umidade e água, que brotava enquanto matéria, 
mas ainda não sabia bem o que fazer com ela. A umidade deixa seu rastro, seu vestígio, que vou pensar com o auxílio de Jean Luc Nancy. Como a neblina só evapora com o calor, Aquecedor passa a ser a próxima etapa, sugerindo então a presença e uso de um dispositivo - convocando Giorgio Agamben - como elemento fundamental para dissipá-la e tornar a visão menos turva. Deixar mais claro aquilo que estava presente, mas escondido pela névoa metafórica, querer acessar seu vestígio. A atmosfera aquecida pode então causar Precipitação. 0 trabalho se materializa, adquire forma própria. 0 jardim se dobra em exposição e filme, cada um com suas particularidades, para em seguida vir a Irrigação. Irrigar o solo dos pensamentos dessa tese, apresentando os artistas e teóricos que me ajudaram a definir as bases para o plantio e desenvolvimento das ideias aqui propostas. Milton Santos, Augustin Berque, Michel Serres, Anne Cauquelin, Giuseppe Penone, João Modé, Brígida Baltar, entre outros, regaram e continuam regando e adubando meu jardim e minha floresta.

No questionamento central dessa tese sobre possíveis relações entre arte contemporânea e natureza, penso na matéria água como o primeiro elemento condutor de pensamento. É no fluxo da água que minhas ideias vão surgindo e vou achando as direções a seguir. A arte reage ao mundo de acordo com a relação que o ser humano tem com seu meio, seu contexto histórico e com os meios tecnológicos disponíveis. Penso na matéria água com o seu potencial de assunto cultural, político e econômico, trabalhado em diversas propostas artísticas, dependendo do estado em que se encontre ou que seja sugerido. Quero me aproximar dela considerando sua concretude, sua força enquanto matéria, sua riqueza e importância enquanto recurso natural. A água é o principal elemento constituinte do planeta e do nosso corpo, fundamental para a manutenção da vida no planeta. Águas é o primeiro subtítulo dentro do capítulo 2 chamado $O$ universo de água. Nele, exponho o ciclo das águas, demostrando que hidrosfera, atmosfera e litosfera interagem e se complementam. Recorro ao cineasta chileno Patrício Guzmán, em seu filme Nostalgia da Luz, para lembrar sobre a necessidade da existência de umidade para a geração e continuidade da vida. A artista Sara Ramo também é convocada, com seu vídeo Oceanos, reforçando a multi-funcionalidade essencial da matéria água. Em 
seguida, as Barragens, que são construções humanas que visam reter a água fluida para gerar energia e riquezas na divisão geopolítica global. A água como commodities, disputada entre nações e povos no mundo e no Brasil. "Watercolor", curto vídeo do belga Francis Alÿs toca nesse assunto de forma inteligente e sutil. “Existem agora lagos de homens, agentes físicos no sistema físico da Terra"iv, é a primeira citação de Michel Serres, autor que vai conduzir a discussão sobre o atual convívio conflituoso entre homem e natureza.

Sabemos que é necessário preservar as Nascentes de água para garantir o abastecimento dos rios e manter o perfeito funcionamento do ciclo aquoso. Elaboro, então, um paralelo entre o ateliê de um artista e a ideia de nascente. Relaciono o espaço do ateliê à ideia de nascente, mesmo sabendo que a criação artística prescinde de localização exata para nascer. Sem querer sacralizar ou romantizar esse espaço, atribuo-o a possibilidade de ser nascente, no sentido de ser local onde surgem ideias, experimentos e materializações. O artista Daniel Buren e a historiadora e crítica de arte Marisa Flórido me apoiam nessa ideia. Crio o termo ateliê-mina, pensando no meu espaço particular de ateliê onde brota a matéria água que vai conduzir o fazer de Um jardim em Floresta. Penso no meu ateliê como centro gerador da matéria prima que dispara e norteia todo o processo desse trabalho. Denomino então esse espaço nascente e doador de ateliê-mina. Trago o pensamento de Milton Santos de que a relação do homem com a natureza é mediada por tecnologias. $O$ homem se relaciona com seu meio natural e estabelece uma troca por meio de técnicas. É o caso da minha experiencia no ateliê-mina. A umidade do ambiente, o vapor de água presente no espaço só é transformado em água pelo uso de uma tecnologia, de um dispositivo, os desumidificadores, máquinas capazes de condensar e materializar o invisível em paupável.

No fluxo do pensamento encontro nas Nuvens, que carregam vapor de água para abastecer nossos rios e bacias, uma constatação de natureza alterada, comparando uma clássica tela do pintor William Turner com uma série de fotografias de John Pfahl. 0 geógrafo Milton Santos e o filósofo Félix Guattari, guiarão a discussão de um ponto de vista científico-político, que encontrará em Jacques Ranciére uma 
aproximação com o trabalho especificamente artístico. Essa transformação da matéria, essa natureza alterada, vai aparecer em dois trabalhos da artista Marta Jourdan, que encerram o capítulo com a ideia de natureza como fluxo e arte como a experiência desse fluxo. Já em Rio, sigo o fluxo de dois artistas. Giuseppe Penone e seu 'ser rio', onde a forma da pedra se molda pelo rio e onde o artista se propõe a ser rio. E Riverbed, de Olafur Eliasson, que concebe um leito de rio dentro do espaço de um museu, transformando assim a experiência da arte e da natureza. Descubro que existe um fenômeno natural, os cursos de água atmosférica, que são formados por massas de ar carregadas de vapor de água, muitas vezes acompanhados de nuvens. Os ventos são os responsáveis por impulsioná-los, deslocando umidade da Bacia Amazônica para o Centro-oeste, Sudeste e Sul do Brasil, num fluxo continental. Recebem poeticamente o nome de rios voadores. Busco nesse conceito científico uma aproximação com Um jardim em Floresta como um rio voador, que retém aqui para escoar em outro lugar.

Parto para a caminhada entre jardins. A primeira coisa a fazer é defini-los quanto aos estilos históricos. "É a natureza desenhada e controlada pelo homem, para o homem", dizia Burle Marx. O jardim sem canteiros é o título do capítulo 3 dessa tese. A lógica é caminhar das definições de jardim até chegar à imensidão de uma floresta. Belvedere, assim é chamado o mirante de onde se pode ter uma visão panorâmica de um jardim e seus canteiros específicos, é também o primeiro subtítulo desse terceiro capítulo. Nele, passeio pelas descrições de estilos históricos levada pela pesquisa de Carlos Terra e pelo pensamento de Roberto Burle Marx, de que um jardim deve ser "uma obra de arte como uma pintura, uma escultura, uma sinfonia, uma tapeçaria"v. Um modo de pensar o jardim como uma estrutura moderna, com seu rigor geométrico, mas sem deixar de lado a importância de um profundo conhecimento botânico. Um jardim como um espaço delimitado, tal qual sugere sua etimologia nórdica garth, que significa cerca.

Encaminho-me para os Canteiros, pensando sobre a funcionalidade e especificidades dos jardins e encontro jardins flutuantes, que me remetem à ideia de jardim-voador por sua mobilidade. Passo a enxergar o jardim como uma heterotopia, pelo olhar de 
Michel Foucault, que sugere o jardim como "um espaço sagrado que reiterava nos seus quatro cantos os quatro cantos do mundo, com um espaço supra-sagrado no centro, um umbigo do mundo, ocupado pela fonte de água”. 0 jardim então se expande e afrouxa a rigidez de sua cerca. Encontro eco em uma pesquisa de um professor polonês, chamado Mateusz Salwa, que propõe pensar o jardim como performance, incorporando a ação humana como parte fundamental da dinâmica de um jardim. 0 corpo humano com todos os seus sentidos é ativado quando num jardim, sugerindo uma diminuição da primazia da visão para invocar uma interação. Lembro da obra Vær $i$ vejret ${ }^{v i}$, de Olafur Eliasson instalada no jardim do Museu Ordrupgaard, na Dinamarca. Aqui a interação supera a visibilidade. Já em Alamedas, povoadas de árvores, nos conduzem os caminhos e o passeio entra pelo museu que incorpora o jardim como obra. A exposição Pode o museu ser um jardim?, no Museu de Serralves de Porto, Portugal, propõe pensar os dois espaços e revela a intenção de aproximação entre eles, inclusive por apresentar uma troca dos trabalhos expostos assim como a mudança de estações do ano. Dos muitos artistas expostos, me interesso particularmente pelo trabalho Grass Grows, de Hans Haacke, que desloca para dentro do espaço expositivo o ciclo natural que acontece no ambiente exterior do jardim. Trago também para discussão dois trabalhos de Eduardo Coimbra, que fazem deslocamentos opostos. Natureza da Paisagem, exposição no MAM RJ, instala um tapete verde e vivo dentro do ambiente moderno de concreto armado, enquanto Passarela monta uma estrutura arquitetônica em plena Mata Atlântica do Museu do Açude. Ambos evidenciam a circularidade da natureza.

Campo, terreno sem mata e alusão ao campo ampliado, traz a discussão da interação da arte com o espaço da natureza na land-art em dois vieses diferentes. 0 do domínio e conquista e o do convívio e integração. Aqui, Michael Heizer e Richard Long dialogam, cada um em sua escala própria. Bosque é o subtítulo que vem a seguir, lugar por definição aprazível e possivelmente florido, que aqui traz a disputa entre homem e natureza como ideia central apontada novamente por Michel Serres. Convido o artista Rodrigo Braga para uma conversa. A partir do seu vídeo Tônus, Braga, nascido em uma família de cientistas, expõe sua relação artística com a natureza, atravessada pela biologia e ecologia. "É esse lado de quem avilta quem", 
provoca o artista. Trago então o termo Antropoceno, que vem sendo utilizado por alguns cientistas para aludir a uma nova camada geológica que registra comprovadamente a ação humana na Terra. É a iminência de uma nova era que se inicia em estado de alerta que coloca em risco a vida humana na terra. Outro convidado para conversar sobre sua produção é João Modé. Mata traz a transcrição dessa conversa que foca em dois trabalhos de Modé: O passado vem de frente numa brisa, instalado no Museu do Açude e Para o silêncio das plantas, exposição nas Cavalariças do Parque Lage. A poética de intervenções e instalações sutis do artista se relaciona diretamente com o espaço a ser habitado. Esses trabalhos negociam diretamente com a natureza, convocando-a a agir com eles, tornando-a sujeito, agente e parceira. Modé se relaciona de forma viva com os ciclos da natureza, o que me remete à proposta de Jacques Ranciére de que a arte que enfrenta o sopro da natureza viva, "se opõe a superfície muda dos signos pintados"vii.

Chegamos a Floresta, subtítulo que encerra a discussão proposta nessa tese. Aqui a constatação da enorme diferença entre o tempo humano e o tempo da natureza, pela minha própria vivência durante uma residência dentro da floresta amazônica. Relato a experiência nesse lugar-floresta e rio-mar, e apresento alguns experimentos realizados no período. Como último artista e obra, Grande Budha, de Nelson Félix. Obra que sempre me encantou e intrigou e de certa forma disparou a hipótese central dessa tese, de que a natureza é convocada como parceira em determinados trabalhos de arte. A natureza viva é sujeito e agente na arte contemporânea.

Ao longo dessa tese venho tecendo um pensamento que aponta para uma possível e potente relação entre natureza e arte contemporânea, onde a arte assume nova posição em relação à natureza. A natureza passa a não ser apenas fonte de matéria e de contemplação, de estudo e de observação, para ocupar o lugar de agente. A visão não é mais o único sentido convocado pelos trabalhos de arte. A natureza aparece com sua instabilidade, imprevisibilidade e inconstância. Surge um novo olhar para a natureza, que a transforma de objeto a sujeito. Acredito que alguns artistas vêm dando espaço para que ela se torne parte integrante do trabalho, percebendo sua 
potencialidade de parceria. Venho pensando em uma relação simbiótica entre arte e natureza, uma complementando o trabalho da outra. A natureza como parte integrante e atuante do trabalho, agindo como co-autora das obras. Sem a presença e atuação dela esses tais trabalhos não se completam.

Percebo que me reconheço no cartógrafo de Suely Rolnik, que nos diz que a cartografia geográfica nada tem de estática pois segue a dinâmica das mudanças dos terrenos. Essa ideia pode ser associada também ao que ela chama de cartografia psicossocial, que é ao mesmo tempo o fazer e o desmanchar de certos mundos por tentar sintonizar com afetos contemporâneos "mergulhado nas intensidades de seu tempo". Constato que no meu fazer artístico e na minha pesquisa teórica vou absorvendo "matérias de qualquer procedência", "de fontes as mais variadas, incluindo fontes não só escritas e nem só teóricas". Fontes de origens distintas me interessam e me despertam ideias. De textos teóricos a programas de TV, de trabalhos de artistas a matérias científicas vou trançando uma rede de pensamentos, tecendo a variedade e riqueza de inputs. Meus questionamentos "podem surgir tanto de um filme quanto de uma conversa ou de um tratado de filosofia". 0 cartógrafo de Rolnik é um antropófago, que se alimenta e se apropria de fontes para devolvê-las ao mundo com novos valores. 0 que ele quer "é mergulhar na geografia dos afetos e, ao mesmo tempo, inventar pontes para fazer sua travessia: pontes de linguagem". Quanto aos procedimentos de pesquisa, "estes tampouco importam, pois ele sabe que deve "inventá-los" em função daquilo que pede o contexto em que se encontra."viii E nessa forma de agir, o cartógrafo se assemelha ao fotógrafo, que vai pelo caminho encontrando instantes, recortando mundos, criando visualidades e contando histórias. Histórias que abrem caminho para outros pensamentos, para novos modos de agir, para novas interações com o mundo.

A seguir, seguem, em resumo, as principais discussões de cada um dos três capítulos. 
0 relato da Umidade

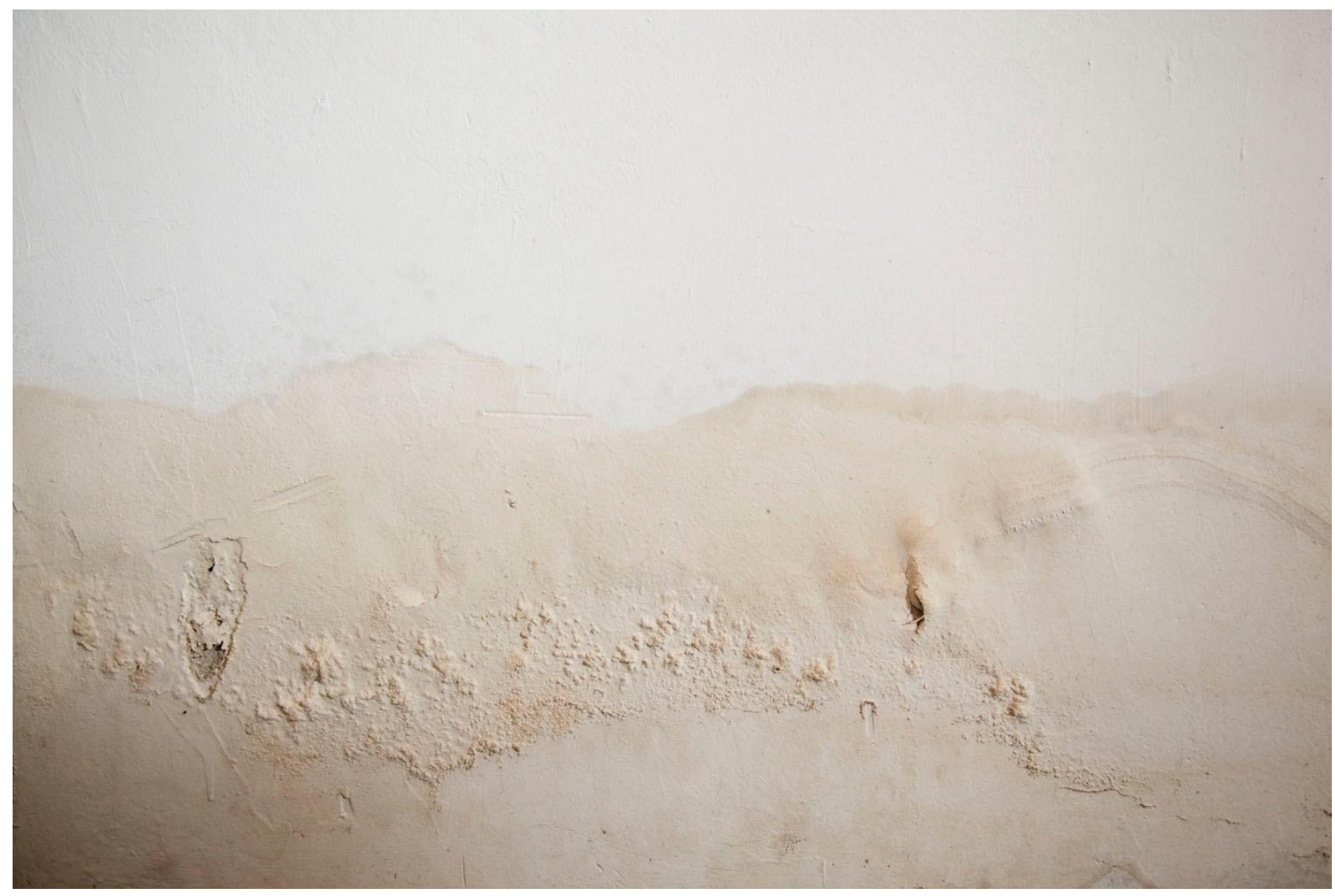

Claudia Tavares, Um jardim em Floresta, fotografia, 2014/2018

Durante os quatro anos em que o trabalho se desenvolveu, vários pensamentos e questionamentos surgem embaralhados. Alguns foram abandonados, enquanto outros persistiram. Questionamentos diretamente ligados ao trabalho em relação a suas possíveis formas de apresentação, sua potência, suas familiaridades, suas teorias. É ele que irriga o solo das ponderações e me abre um horizonte mais amplo, um campo de pensamento onde brota a dupla natureza e arte. Passo a me perguntar: como se relacionam?

Obviamente essa pergunta é muito reducionista e não dá conta da complexidade das possíveis relações entre arte e natureza ao longo da história da arte. Escolho então reduzir o campo e focar em pensar sobre a relação da arte contemporânea com a natureza, pela produção de determinados artistas. Penso, com as palavras do geógrafo Augustin Berque, para quem a natureza é: 


\begin{abstract}
“...de fato aquilo que em si não é definido nem para nem pelo homem; mas sim que é definido no homem e em torno dele. Pelo homem e para ele, a natureza é traduzida obrigatoriamente em termos próprios a uma cultura; ela é integrada ao mundo que o homem é capaz de conceber, de perceber e organizar. Ao mesmo tempo, a natureza em si não deixa de existir, em seu sentido próprio, que é irredutível aos termos humanos, ou seja, não somente em relação ao homem (em seu ambiente, do mais próximo ao mais distante), mas também no próprio homem (em sua fisiologia). A natureza, essa entidade que é por vezes inconcebível, incomensurável, mas na qual o homem está imerso, que ele carrega em si mesmo e que ele não cessa de humanizar, de cultivar, a natureza portanto, por sua ambivalência, é o exemplo de uma realidade mesológica: indissoluvelmente factual e sensível, física e fenomenal, a natureza é bipolarix".
\end{abstract}

A natureza é física em suas plantas, rochas, oceanos, seres vivos e fenomenal enquanto chuva, vento e clima. É fluxo e ciclo. Nos circunda, nos provem, nos orienta, nos constitui. É aquilo que deixa prover de si. A natureza constitui o fundo essencial a partir do qual tudo pode surgir. Gosto de pensar nessa realidade mesológica que aponta para as relações recíprocas entre homem e o meio em que ele vive. Um atinge e influencia o outro e vice-versa. A umidade do meio me afeta e eu respondo a esse afeto, artisticamente. "A relação entre o homem e seu entorno é um processo sempre renovado que tanto modifica o homem quanto a natureza"x, palavras de Santos. Acredito que essa seja a direção que aponta para os meus intercessores, para a produção dos artistas que vem me impressionando, me irrigando. Artistas que admiro lidam com a natureza em seus trabalhos de uma forma simbiótica, parceira, onde a ação artística provoca uma reação da natureza. Me interesso pelo o que a ação do artista provoca na natureza e como ela responde aos trabalhos, se tornando parte integrante deles. Me refiro aos trabalhos onde a resposta da natureza completa e complementa o trabalho, uma arte relacional. São essas fontes que, ultimamente, mais irrigam minhas ideias. Posso dizer que Nelson Félix, Brígida Baltar, João Modé, Olafur Eliasson, Guiseppe Penone, Richard Long, Rodrigo Braga, entre outros, são minha família artística e é com eles, com suas obras e suas falas, que me desloco nessa construção de jardim e de tese.

Entretanto, desperta minha atenção desde o início da pesquisa para a escrita a impressão que a conexão arte x natureza, pelo ponto de vista da estética, parece ser sempre mediada pelo conceito de paisagem. Paisagem inicialmente vista como uma visualidade da natureza. Encontro inúmeros textos onde esse conceito aparece para 
referir ao trabalho de artistas que lidam com a natureza, seja por representação, observação ou interferência. Falo aqui da ideia primeira de paisagem enquanto representação visual de um país, o que parece ter sido a base para 0 desenvolvimento da pintura paisagística do século XVI. Penso também na relação impressionista de representação das nuances da natureza, expressas pela luz e cores, pela experiência da pintura a plein-air. As impressões instantâneas da apreensão da luz e do tempo. Penso ainda na land-art, que, de modo muito geral, foi a inauguração da interferência direta da arte nos espaços abertos da natureza. Não é possível falar da land-art como um movimento uniforme, visto que os artistas encaixados nessa denominação agem na natureza de formas díspares e com escalas diversas. Voltarei a falar disso mais adiante, trazendo os deslocamentos do inglês Richard Long, um dos artistas que regam meu jardim. Até então, percebo que, na literatura da arte, em todas essas experiências artísticas mencionadas acima, o termo paisagem se faz presente. Pesquisar esse conceito em todo sua complexidade seria o trabalho de uma outra tese, longe do meu objetivo aqui. Me apoio então nas ideias de Anne Cauquelin e Milton Santos, para pensar paisagem em diferentes campos.

As paisagens são muito mais que imagens da natureza para Milton Santos, que embora pertençam ao domínio da visão, também inclui movimentos, odores e sons, extrapolando a visualidade. A paisagem contemporânea na geografia "não é dada para todo o sempre, é objeto de mudança. É um resultado de adições e subtrações sucessivas"xi. Santos concebe a paisagem como a expressão materializada do espaço geográfico, espaço de ação do homem, interpretando-a como um conjunto de formas, que, num dado momento, exprime as heranças que representam as sucessivas relações localizadas entre o homem e a natureza. A paisagem se sedimenta com as transformações da sociedade. No campo, na cidade e mesmo na floresta, camadas de tempo vão se sobrepondo. Ao geógrafo cabe ler a sociedade pela paisagem que esta produz. Na paisagem está contida a história da relação sociedade-natureza. 
Anne Cauquelin está interessada em descobrir quando surge a noção de paisagem como representação figurada da natureza, como "esquema simbólico de nosso contato com a natureza"xii. De volta a Grécia, não encontra a palavra nem o termo paisagem, mas constata que mesmo não havendo paisagem, a natureza está presente. Physis existe em grego. Paisagem não. Então me pergunto, a ausência da paisagem inabilita a natureza? Não. Cauquelin responde "a natureza não era figurada na forma de paisagem"xiii. A paisagem é, portanto, uma construção cultural, o conjunto de uma série de ideias, que as leis da perspectiva aplicadas à pintura, legitimam. Não é o que está a sua frente e sim o que se vê. Ela começa como ornamento e cenário, depois se torna toda a pintura, configurando aí um gênero: a pintura de paisagem. Mas aquilo que surge discretamente e é percebido apenas como uma técnica de representação será um grande marco de nossa cultura visual. "É por meio da arte que digo o que vejo que devo ver na natureza. E o que vejo dessa maneira é paisagem".

A paisagem no sentido estético, segundo Cauquelin, é uma figuração da natureza que contem um enquadramento do olhar que surge com a invenção da perspectiva, enquanto que na geografia de Santos a paisagem é relacional, inscrição da atividade humana na terra, no planeta. Me identifico muito com a segunda visão, a do ponto de vista geográfico. Interação mais que visualidade. 0 trabalho fotográfico de $U m$ jardim em Floresta não nega as regras visuais da composição e enquadramento, mas nasce da convivência com a umidade e se constitui, se corporifica pela fotografia. A visualidade surge da interação. Opto por adotar aqui o termo natureza enquanto matéria de convívio e troca.

Voltando ao relato da minha experiência, a primeira coisa que percebo é o lugar do ateliê como fonte de matéria. Um jardim em Floresta nasce desse ambiente específico, determinado, com endereço próprio. Se não tivesse habitado o ateliê, não teria convivido com a umidade, não teria despejado água na pia, não teria pensado no sertão, ou ao menos, não dessa forma. A natureza em estado bruto, ali presente, me afeta. Uma natureza doadora, que me oferece uma matéria a ser trabalhada. A ponte entre dois locais tão distintos é lentamente construída por conta do excesso 
de umidade daquele lugar. Penso então que o papel do ateliê passa a ser o de protagonista, levando em conta a natureza presente. Denomino-o ateliê-mina. 0 ateliê que mina umidade e o jardim construído no sertão. 0 que os une é a água, esse recurso natural tão precioso. Volto a pensar na relação entre arte e natureza que tem como base um lugar de convívio e parceria, até mesmo de simbiose. A natureza como parceira da arte. A natureza que responde e trabalha junto do artista. 


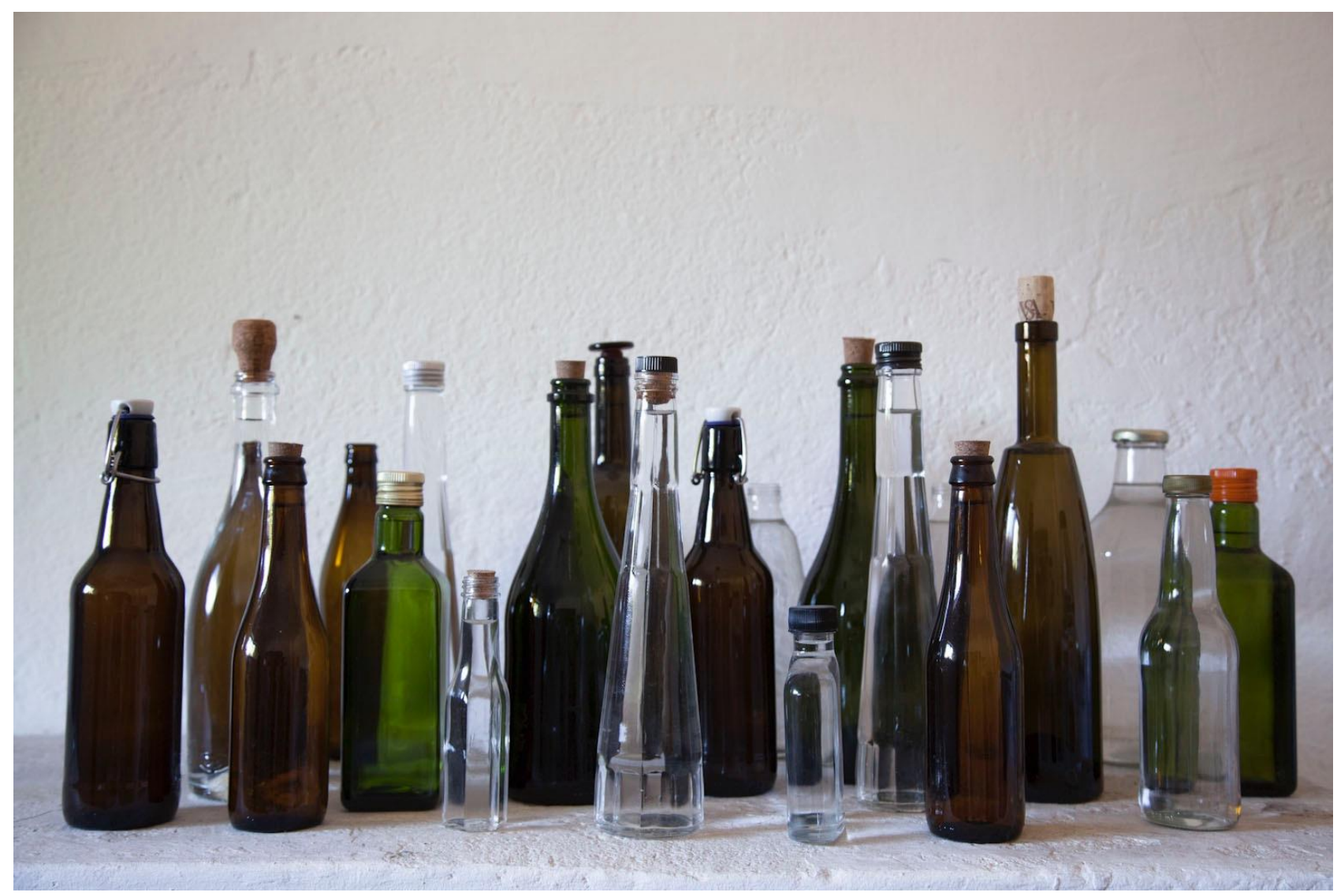

Claudia Tavares, Um jardim em Floresta, fotografia, 2014/2018

“Apesar de sua extensão, ninguém o vê. É que esse rio não tem margens nem peixes. É um rio metafórico - mas não inexistente - formado por uma coluna de vapor de água com cerca de 3 quilômetros de altura, algumas centenas de quilômetros de largura e milhares de extensão"xiv. Existe um fenômeno natural que são os cursos de água atmosférica. Eles são formados por massas de ar carregadas de vapor de água, muitas vezes acompanhados de nuvens. Os ventos são os responsáveis por impulsioná-los, deslocando umidade da Bacia Amazônica para o Centro-oeste, Sudeste e Sul do Brasil, num fluxo continental. Recebem poeticamente o nome de rios voadores, popularizado pelo professor e pesquisador José Marengo do CPTEC, Centro de Previsão de Tempo e Estudos Climáticos.

"A maior parte do vapor d'água vem do oceano, transportada para o continente pelos ventos alíseos, que sopram de leste para oeste - uma pequena porção dessa umidade se condensa em nuvens e cai como chuva sobre a Amazônia. Mas boa parte do vapor que forma esse rio invisível 
vem da própria floresta. É que, ao passar sobre a maior floresta tropical do planeta, ele incorpora a água que evapora diretamente do solo e também aquela retirada pelas plantas da terra e lançadas na forma de vapor na atmosfera. Uma parte da água da Amazônia chega ao sul do país e possivelmente vira chuva. ${ }^{\mathrm{xv}}$

Assim como os rios voadores são passageiras e transitórios, a relação entre homem e natureza se modifica no desenrolar da nossa longa história. 0 conceito de natureza não é fixo, varia de acordo com o conjunto de verdades que dimensionam a realidade de cada etapa da humanidade. Ideias passam, percepções se transmutam. "Com a presença do homem na Terra, a natureza está sempre sendo redescoberta"xvi, diz o geógrafo Milton Santos. Antes da presença do homem, o que havia era só a natureza. A partir da existência humana o mundo natural tem seu sistema alterado. 0 planeta passa a ser o habitat dos seres humanos.

“O planeta Terra vive um período de intensas transformações técnico-científicas, em contrapartida das quais engendram-se fenômenos de desequilíbrios ecológicos que, se não forem remediados, no limite, ameaçam a vida em sua superfície”, diz Felix Guattari, que identifica que as instâncias políticas não parecem capazes de reconhecer e lidar com tal problemática. Aponta que somente o que chama de ecosofia, ou seja, a articulação entre meio-ambiente + relações sociais + subjetividade pode ser a solução para os problemas de ordem ecológica, e que essa articulação deve se dar em escala planetária, "com a condição que se opere uma autêntica revolução política, social e cultural reorientando os objetivos da produção de bens materiais e imateriais"xvii. Divide a ecosofia em duas: a social, baseada na reinvenção de maneiras de ser nas relações de casal, família, contexto urbano e de trabalho; e a mental, que reformula a relação do sujeito "com o corpo, com o fantasma, com o tempo que passa, com os 'mistérios' da vida e da morte". Essas propostas estabelecem a necessidade de reorganizar as relações entre os seres humanos, entre o sujeito e sua subjetividade, além de entender a natureza como uma aliada e não como fonte incondicional de subsistência. A ecosofia social e mental constituem a revolução que se faz urgente, que para Guattari, é a única ordem de vivência humana possível no mundo global contemporâneo. 
Voltando a Santos, o geógrafo propõe um questionamento em relação ao que distingue o homem de outras formas de vida. Ele sugere que são respostas possíveis e corretas a possibilidade da fala como a grande distinção pela habilidade de construção de uma linguagem própria, ou que o homem é o único animal que consegue se sustentar apenas nos membros inferiores assumindo uma postura ereta e todos os favorecimentos que isso lhe traz, ou que sua capacidade de reflexão é o grande fator de diferença entre outros animais. Todas essas respostas para Milton Santos são insuficientes. Para ele, o que distingue o homem de outras formas de vida é o trabalho. "O fator distintivo determinante é o trabalho, o que torna o homem uma forma de vida sui generis é a capacidade de produzir". xviii Define trabalho como a capacidade de uso da energia e força própria sobre a natureza, com ou sem o uso de equipamentos mecânicos, com o intuito de reprodução da vida individual e grupal. Diferente de outros animais, o homem se relaciona com a natureza por meio da invenção, fortalecendo e potencializando sua inteligência. Por meio de gestos inventivos estabelece um "processo de troca recíproca e permanente entre homem e natureza".xix Guattari vai sublinhar que o trabalho humano vem se modificando frente a revolução informática, robótica e genética, o que produz novamente uma transformação no habitat. Se a forma de produção se modifica, se remodela também a relação entre homem e natureza.

Mas como então pensar o trabalho artístico dentro dessa afirmação do trabalho como diferencial entre homem e outras formas de vida? Acredito que a intervenção do pensamento de Jacques Ranciére se faz necessária agora. Abrindo um paralelo ao pensamento de Santos e Guattari, trago o pensamento de Ranciére sobre o trabalho artístico, em A Partilha do Sensível. Rancière tende a ver as práticas artísticas como formas modelares de ação e distribuição do comum, tendo em vista que o comum é a cultura, os direitos/deveres e liberdade. "Qualquer que seja a especificidade dos circuitos econômicos nos quais se inserem, as práticas artísticas não constituem uma excessão às outras práticas. Eles representam e reconfiguram as partilhas dessas atividades". xxA arte relaciona o fazer, o ser, o ver e o dizer daquilo que é comum e ao mesmo tempo particular. Ela consiste num trabalho comum, e que como tal tem apenas as especificidades tecnológicas e sensíveis características de 
qualquer fazer. 0 trabalho que diferencia os homens dos outros animais, como nos aponta Santos, inclui o pensar artístico. "Mais do que nunca a natureza não pode ser separada da cultura e precisamos aprender a pensar 'transversalmente' as interações entre ecossistemas, mecanosfera e universos de referência sociais e individuais"xxi, conforme Guattari. E pensar a natureza pela arte hoje é responder ao mundo que é contemporâneo aos artistas, com suas fragilidades, crises, limitações e incertezas.

Seguindo adiante de acordo com a proposta de Santos, pensamos que a relação do homem com a natureza é reciprocamente progressiva e dinâmica. A ação humana age no espaço geográfico, a forma de vida humana é a criação do espaço. A geografia é a ciência do espaço do homem. O homem impõe modificações e acréscimos no espaço natural que se pode chamar de cultura e história. A natureza vai absorvendo essas novas formas culturais e históricas e vai sofrendo um processo de culturalização. “No processo de desenvolvimento humano, não há uma separação do homem e da natureza. A natureza se socializa e o homem se naturaliza."xxii Essa relação passa a ser mediada por tecnologias. 0 homem se relaciona com seu meio natural e estabelece uma troca por meio de técnicas. É o caso da minha experiencia no que chamei de ateliê-mina. A umidade do ambiente, o vapor de água presente no espaço só é transformado em água pelo uso de uma tecnologia, de um dispositivo, os desumidificadores, máquinas capazes de condensar e materializar o invisível em paupável.

A natureza que é fluxo, cria fenômenos que se iniciam em um determinado espaço e tempo e vão agir em um outro espaço em outro tempo, as vezes percorrendo distâncias continentais, como é o caso dos rios voadores, que se iniciam como evaporação no oceano atlântico nas bordas do estado da Amazônia e vão desaguar como chuva a milhares de quilômetros de lá. Pensando nisso, volto ao livro Contrato Natural e me lembro de um trecho onde Michel Serres vai apontar a ideia de que um mínimo movimento de bater da asa de uma borboleta vai ecoar no tempo e no espaço. “...a borboleta descrita por Swift, cujo batimento de asa, num deserto da Austrália, ressoará pelas pradarias da verde Erin, talvez amanhã ou dentro de dois 
séculos, sob a forma de tempestade ou brisa acariciadora, segundo a oportunidade"xxiii. Pensamento borboleta, efeito furação. Serres se refere à atuação humana em relação a natureza. Anuncia a necessidade, hoje muito evidente, de uma nova relação com o mundo o qual estamos degradando e poluindo incessantemente. O lugar da natureza enquanto objeto de exploração constante do homem deve urgentemente ser revisto. É preciso estabelecer limites e definir novamente papéis. Se devastarmos a floresta Amazônica, por exemplo, acabaremos com os rios voadores que abastecem as bacias do centro-oeste e sudeste do Brasil. Causa e consequência, uma relação direta. É isso que propõe Contrato Natural, escrito em 1990. "Ela pressupõe que nós, os homens, estamos no centro de um sistema de coisas que gravitam à nossa volta, umbigos do universo, donos e possuidores da natureza". 0 homem estabelece regras de relação social, porém não considera contratar limites em sua convivência com o mundo natural, a partir do desenvolvimento das ciências e das técnicas associadas ao uso industrial e comercial para a geração de conforto e alimento. Subtende-se desse pacto que a natureza pode ser apropriada para prover as necessidades econômicas da sociedade indefinidamente. A natureza, enquanto objeto mantido durante longo tempo sem direitos, reage de forma própria e assustadora, no mais das vezes e mais recentemente. 0 livro alerta sobre o impasse que pode custar a perpetuação da espécie humana. "A Terra existiu sem os nossos inimagináveis antepassados, poderia muito bem existir hoje sem nós e existirá amanhã ou ainda mais tarde, sem nenhum dos nossos possíveis descendentes, mas nós não podemos existir sem ela"xxiv. Essa constatação nos coloca à beira de um abismo. "Cada vez mais, os equilíbrios naturais dependerão das intervenções humanas", constata Guattari. É hora de reposicionar as relações, estabelecendo uma vinculação simbiótica e não mais de domínio unilateral. Milton Santos nos diz: "No processo de desenvolvimento humano, não há uma separação do homem e da natureza. A natureza se socializa e o homem se naturaliza". xxv Guiseppe Penone parece concordar quando afirma que não há escala hierárquica entre homem e natureza, que o homem não é superior a ela, ele é um elemento que pertence a ela, um ser natural assim como uma pedra. Propõe uma comparação entre a pedra que está há milhares de anos na natureza e o homem 
que tem uma duração muito limitada se comparado a pedra, e questiona se um é mais importante que o outro e que é preciso considerar essa questão.

0 jardim sem canteiros

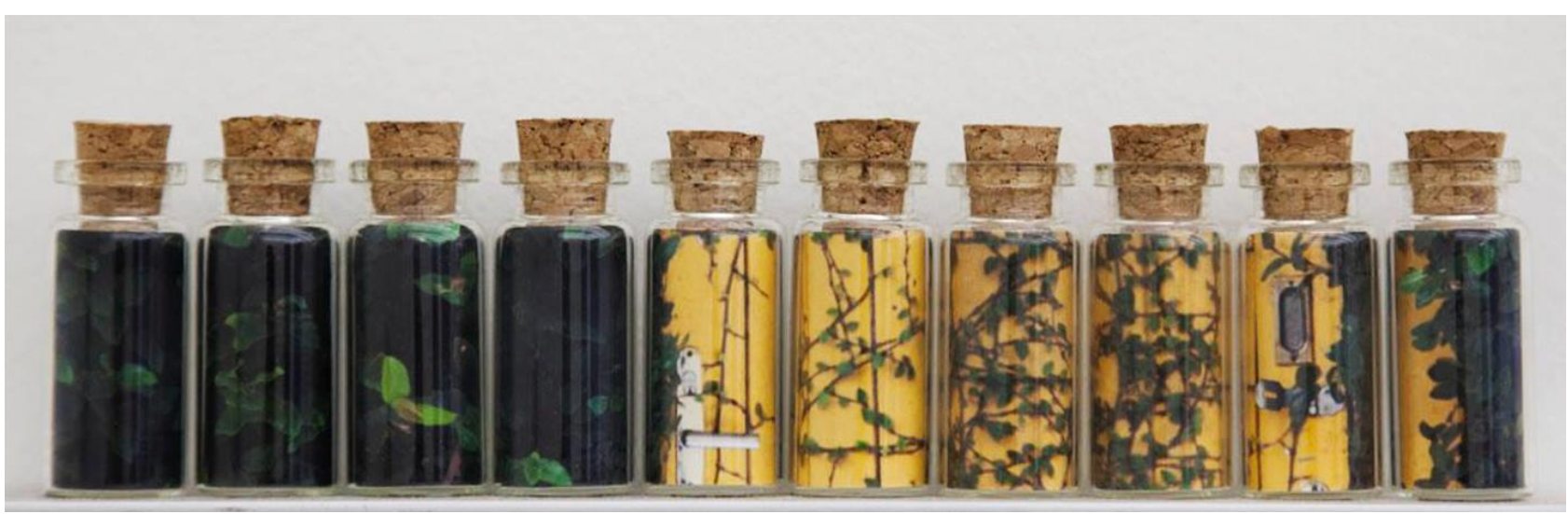

Claudia Tavares, Um jardim em Floresta, fotografia, vidro e cortiça, 2014/2018

Terreno delimitado, predominantemente cultivado com plantas ornamentais, indicado ao lazer e à fruição estética, a palavra jardim pressupõe, em sua etimologia, algo fechado. Sua origem, proveniente das línguas nórdicas e saxônicas, é o radical garth. Garth significa cerca. Essa origem etimológica aponta para a noção de jardim como geralmente o referimos hoje: um espaço com dimensões definidas, um terreno delimitado que contém elementos naturais e artificiais em comunhão, projetado e construído pelo homem para seu próprio uso.

Se pensarmos nas funcionalidades atribuídas aos jardins, encontramos várias denominações de acordo com sua função específica, tais como jardim científico, ligado intrinsecamente ao estudo da botânica; jardim utilitário onde o cultivo é escolhido pela utilidade das plantas, seja medicinal ou alimentar; jardins de prazer que associam elementos decorativos e ornamentais, podendo ser grandes ou pequenos em extensão, públicos ou privados. Todas essas definições e classificações soam como descrições de limitados espaços verdes encontrados em meio a centros urbanos, preocupadas em estabelecer um posicionamento do homem 
criador/paisagista perante a natureza projetada. Como definições cumprem seus objetivos, mas como ideias são restritas.

Penso então nas heterotopias de Michel Foucault. Foucault percebe o valor diferenciado do jardim quando o coloca como uma heterotopia, ou seja, um lugar outro, um lugar que não pode ser definido imediatamente, um microcosmo que possui muitos estratos, um espaço de caráter complexo. Sugere o jardim como talvez a heterotopia mais antiga, mostrando, por exemplo que "na tradição persa, o jardim era um espaço sagrado que reiterava nos seus quatro cantos os quatro cantos do mundo, com um espaço supra-sagrado no centro, um umbigo do mundo (ocupado pela fonte de água)"xxvi. A água, como fonte, como jorro de vida e centro do mundo volta ao texto. 0 centro desse jardim que simboliza o mundo é ocupado por ela em sua riqueza geradora de vida. Foucault afirma que os tapetes persas são a representação tecida em linha de seus jardins, dizendo "o jardim é um tapete no qual todo o mundo atinge a sua perfeição simbólica; e o tapete um jardim que se pode deslocar no espaço". Estar sobre um tapete persa é estar sobre um jardim, estar com o mundo todo em qualquer lugar do mundo. Um jardim então deixa de ser um lugar cercado, garth, e passa a ser aberto para circulação, envolvendo diferentes agentes e territórios.

Encontro um artigo de um professor do Instituto de Filosofia da Universidade de Varsóvia, Mateusz Salwa, que propõe o jardim como performance. Me interesso imediatamente pelo assunto e vou descobrir uma curiosa análise e discussão sobre o espaço do jardim. Salwa afirma que as formas tradicionais de pensar o jardim seriam através da arquitetura, o que envolve o projeto de construção paisagística, da pintura e sua representação visual e da poesia com suas interpretações textuais, e que todas levam em conta prioritariamente a dimensão natural dos jardins. 0 que ele propõe então é aproximar o jardim com a ideia de performance, abrindo uma nova brecha para o pensamento. Diz que é curioso perceber um novo interesse filosófico sobre os jardins, o que segundo ele, vem crescendo nos últimos vinte anos, talvez por uma disposição maior em pensar a natureza ou mesmo pela percepção de que a forma como o jardim tem sido pensado até então pode estar correta, mas 
certamente é deficiente. Afirma ser unânime, no entanto, que pensar o jardim é pensar a dicotomia natureza $\mathrm{x}$ artifício. "In a word, gardens are artifacts based in one way or another on nature". Portanto, "gardens are humanized pieces of nature"xxvii. Salwa investiga o estatuto do jardim como obra de arte, e para isso lança sete perguntas que podem iluminar o caminho. Embora meu interesse aqui não seja esse questionamento específico, aproveito as perguntas propostas para alargar minha própria concepção de jardim. A lista de perguntas inclui as seguintes ideias: jardins não são objetos estáticos para serem contemplados como as pinturas; não são estáveis; fenômenos naturais o influenciam diretamente, ou seja, a presença da natureza os torna imprevisíveis; a autoria não pode ser restrita ao homem; pergunta se seu significado é o resultado do projeto ou da relação homem x natureza; proporcionam multi sensações. Aponta que na arte performativa dos séculos XX e XXI encontramos dinamismo, movimento, instabilidade. Vê nessas características uma semelhança ao status do jardim, que diferente dos objetos estáticos como as pinturas, nos retiram do lugar de espectadores contemplativos e portanto estáticos. Diz: "the architect is the creator of the garden, while visitors, nature and all other elements are performers. In this case there is no passive, distanced audience whatsoever and nature is as active as people involved"xxviii.

A proposição de Mateus Salwa se aproxima do que venho pensando sobre jardim. Assim como ele, penso que jardins são espaços múltiplos, complexos, inconstantes, e o mais significativo, muito vivos. Quando estamos em um jardim, estamos circundados por ele, imersos em sua instabilidade relativa ao ritmo circular de todos os ciclos biológicos envolvidos nas plantas e animais que o habitam. Jardins estão em constante mutação ao longo de dias, décadas, anos e estações, com suas plantas que crescem e morrem, os pássaros que vem e vão nos gramados e copas das árvores, se alimentando e construindo suas moradias, com as formigas que arquitetam suas casas e transportam alimento-folha de um lado a outro, com a fonte de água que enche e refresca o lago para os peixes. Seu caráter é dinâmico, mutável e temporal, devido às constantes mudanças de luz, clima e ventos, influenciando diretamente na freqüência de seus visitantes. Como nos diz Heráclito: nunca se atravessa o mesmo rio duas vezes, o mesmo pode ser aplicado para um jardim. A 
circularidade da impermanência se torna evidente nesse ambiente e para mim essa é a sua grande riqueza. A trajetória circular descreve caminhos sempre novos mesmo percorrendo o mesmo ciclo. Jardins são complexos dinâmicos. Devem à natureza esse dinamismo, esse caráter temporal e mutável, mas não devem só à natureza, como sugere Mateusz Salwa, "gardens are not only visual but also made of everything that might be smelled, heard and touched"xxix. Esse dinamismo é imposto também pela presença humana, que ativa e imprime no jardim a impermanência. Experimentamos e experienciamos a organização racional do mundo natural com nossos corpos convocando todos os nossos sentidos, não apenas com a visão. Olfato, tato e audição também são despertados. Visualidade sim, interação também. Mais um vez o jardim perde suas cercas e se torna um território amplo, instável, colaborativo.

Um jardim é um lugar onde a natureza é construída, é o resultado de um projeto humano que necessita de cuidados externos para se manter sob controle e não se tornar selvagem. 0 jardineiro deve regar sistematicamente seu jardim, podar suas plantas e trocar sua terra de tempos em tempos para garantir seus nutrientes. 0 jardim é o lugar onde se experimenta a natureza esteticamente, embora a visão não seja o único sentido envolvido na experiência de se estar em um jardim. É um ambiente de controle e deleite humano.

Uma floresta encontra seu equilíbrio e sobrevivência na diversidade, no convívio entre espécies distintas. A natureza da floresta não é intocada, mas se auto-regula. É um lugar de alta rotatividade e dinamismo, onde a circularidade da impermanência se evidencia. Enquanto árvores morrem e tombam no chão, outras brotam e crescem em busca da luz. As folhas caídas das árvores que cobrem o chão se decompõem para se tornar alimento para a terra. Animais e insetos são responsáveis pela dispersão das sementes que vão povoando a floresta e espalhando e proliferando suas espécies vegetais. A água das chuvas, das nascentes e dos riachos mantém vivo todo o complexo e abundante ecossistema.

Fazer Um jardim em Floresta é tentar um diálogo entre dois ambientes distintos, o ateliê e o vilarejo, assim como o jardim e a floresta. Floresta, a localidade do sertão 
pernambucano não se assemelha a uma floresta tropical como a amazônica ou a mata atlântica, em seu esplendor verde e úmido, embora seja também um ambiente que se auto-regula na precariedade da seca. Subi a cerca do jardim construído em Floresta com madeiras-galhos de árvores de umbuzeiro, planta abundante da região que, segundo Euclides da Cunha é tida como a "árvore sagrada do sertão". Os índios tupi-guarani sabiam que o umbuzeiro é capaz de armazenar água, especialmente na raiz, qualidade necessária para sobrevivência nos longos períodos de seca na caatinga e o apelidaram sabiamente de "ymbu" ou "árvore que dá de beber" pelo seu fruto, o umbu, fruta aquosa e potente em vitamina C. Pegar as mudas de plantas para o jardim nas redondezas de Floresta é tecer uma rede capilar entre seus doadores, eu e as plantas em si, espécies diferentes que irão conviver e dividir o mesmo espaço. Criar vizinhança entre elas. 0 jardim feito em Floresta não segue as regras de construção dos jardins franceses, nem tampouco dos ingleses, assim como Floresta não é uma floresta verde e úmida. 0 jardim e a floresta são de outra ordem. Ambos pertencem ao território da arte. 
Conclusão

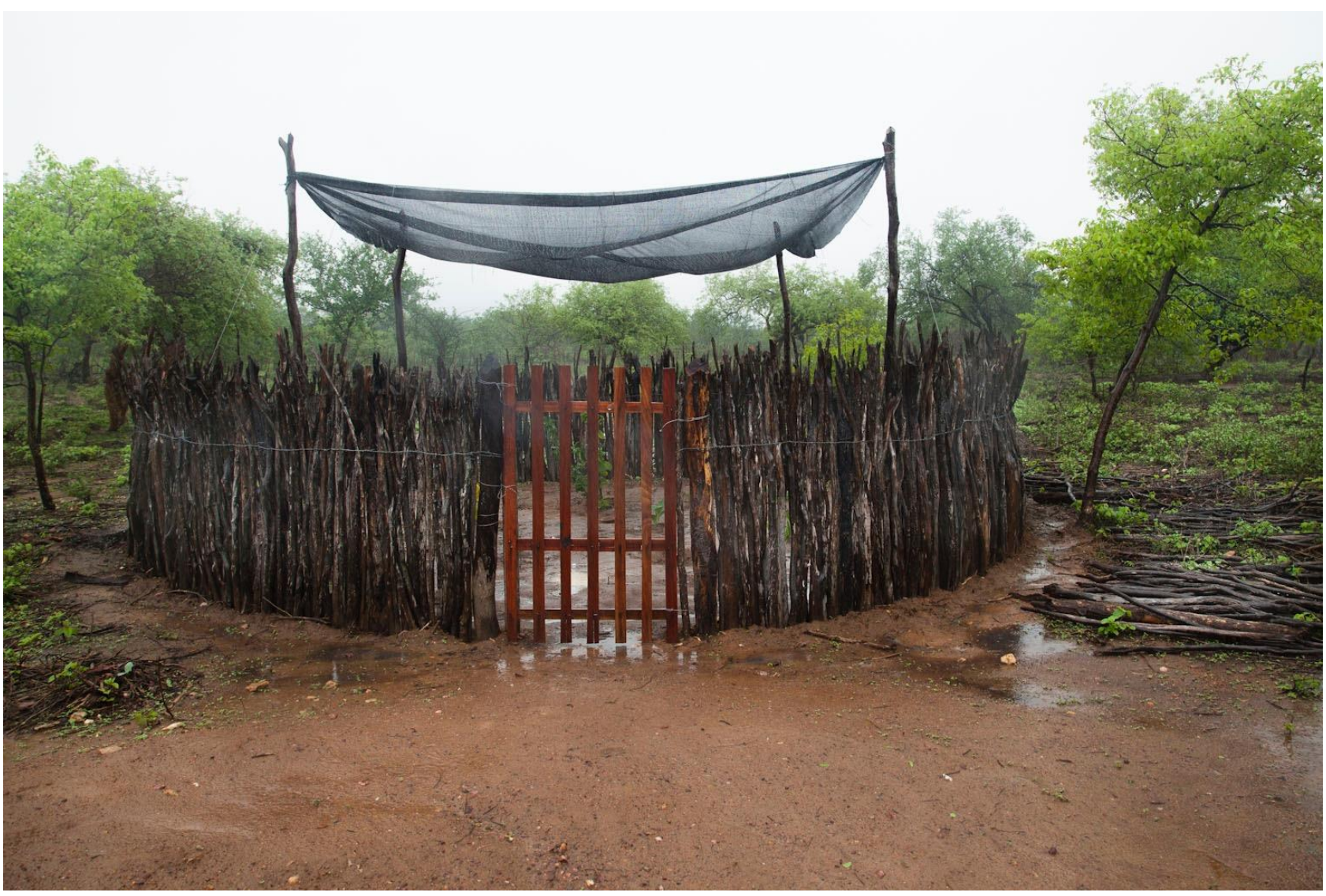

Claudia Tavares, Um jardim em Floresta, fotografia, 2014/2018

O fechamento de um trabalho vem sempre acompanhado da aflição das escolhas.

Escolher é optar por um caminho que deixa de fora outras direções possíveis, outras trilhas não exploradas, outros trajetos interrompidos. Decidir entre um ou outro rumo é buscar evitar desvios insustentáveis. A estratégia então é traçar coordenadas tentando não se perder durante a caminhada, tendo sempre em vista que muitos rios podem levar ao mesmo mar. Na angústia do não incluído se insere também a opção pelas palavras. Como é difícil achar o termo mais acertado para apresentar uma ideia! Corremos o risco de escorregar, tropeçar e cair num terreno não exatamente desejado e assim nos distanciar do curso que havíamos elegido. Mas seguimos na intenção de alcançar a clareza das ideias, apostando na arriscada tentativa de, ainda por cima, escrever com graça e poesia. 
Uso a fotografia como ferramenta para documentar uma ação particular, mas percebo suas limitações. A bi-dimensionalidade, o tempo congelado em uma representação estática, a limitação imposta por sua determinada escala. Pondero os limites da edição, que sempre apresenta muitas possibilidades de inclusão e exclusão de imagens, nas muitas alternativas de sequências e de séries. Deparo-me com essas faltas e encontro no vídeo a possibilidade desse tempo alargado e sempre presente, a chance da inclusão do som e da palavra, que esclarece ideias que as imagens fixas não dão conta por si só. "Pensava em estabelecer uma rota de água, uma espécie de rio voador entre Rio e Floresta"xxx. Penso o filme e a exposição. Acredito na dimensão poética do texto narrado no filme como fio condutor e percebo a necessidade de usar o vídeo para apreciar o tempo que passa, ver a chuva que cai, ouvir o andar sobre os gravetos secos espalhados no chão do sertão. Tanto no filme como na exposição, convido as imagens em movimento a conviver com os instantâneos congelados.

Adoto a rota da água, em sua umidade-mina, que segue em busca do jardim e acaba por levar à floresta. Saio do ateliê úmido rumo ao sertão seco. Experimento essa natureza dicotômica: o excesso de umidade e a secura em demasia. As paredes cobertas de hera versus a falta de verde. 0 jardim é implantado na terra árida e protegido por galhos de umbuzeiro, reproduzindo o modo de fazer das cercas locais. A chuva vem prestigiar a inauguração, deixando verde as redondezas e irrigando potencialmente minhas ideias.

Finalizo com um comentário que ouvi de um artista e que muito me encantou. Ele me disse que eu era a nuvem. Penso na ideia de devir nuvem, que retém aqui para escoar em outro lugar.

Eu-nuvem. 


\footnotetext{
${ }^{i}$ Esse texto, de minha autoria, é a narração do filme Um jardim em Floresta.

ii RANCIÈRE, Jacques, A partilha do Sensível, Editora 34, São Paulo, 2005, pg 15

iii SERRES, Michel - O contrato Natural, Instituto Piaget, Lisboa, 1990, pg 67 e 68

iv SERRES, Michel. O Contrato Natural. Instituto Piaget, Lisboa, 1990, pg 36

v LEENHARDT, Jacques. Jardim e Ecologia em Nos jardins de Burle Marx, Editora Perspectiva, São Paulo, 2010, pg 27.

vi Vær i vejret quer dizer 'estar no tempo', em dinamarquês.

vii RANCIĖRE, Jacques, A partilha do Sensível, Editora 34, São Paulo, 2005pg 21

viii ROLNIK, Suely - Cartografia Sentimental: Transformações contemporâneas do desejo. São Paulo: Editora Estação Liberdade, 1998.

ix BERQUE, Augustim. Paisagem-marca, paisagem-matriz: elementos da problemática para uma geografia cultural. In: CORRÊA, R. L.; ROSENDAHL, Z. (Orgs.). Paisagem, tempo e cultura. Rio de Janeiro: Eduerj, 1998, p. 84-91.

x SANTOS, Milton. Metamorfoses do espaço habitado, Hucitec, 4o edição, São Pualo, 1996, pg 88

xi SANTOS, Milton. Metamorfoses do espaço habitado, Hucitec, 4ํe edição, São Pualo, 1996, pg 61.

xii CAUQUELIN, Anne - A invenção da paisagem. Editora Martins Fontes, São Paulo, 2007, pg 35

xiii CAUQUELIN, Anne - A invenção da paisagem. Editora Martins Fontes, São Paulo, 2007, pg 45

xiv ZORZETO, Ricardo, http://revistapesquisa.fapesp.br/2009/04/01/um-rio-que-flui-pelo-ar/ -

Abril 2009

xv https://www.ecycle.com.br/6721-rios-voadores

xvi SANTOS, Milton - A redescoberta da natureza, aula inaugural Faculdade de Filosofia, Letras e

Ciências Humanas da USP, Março de 1992, pag 4

xvii GUATARRI, Félix, As três ecologias, tradução de Maria Cristina F. Bittencourt, Campinas, Papirus, 1990, pg 9

xviii SANTOS, Milton - Metamorfoses do Espaço Habitado, Editora Hucitec, SP, 1996, 4o edição, pg 87

xix SANTOS, Milton - Metamorfoses do Espaço Habitado, Editora Hucitec, SP, 1996, 4oe edição, pg 88

xx RANCIÈRE, Jacques - A partilha do sensível, Editora 34, São Paulo, 2005, pg 69

xxi GUATARRI, Félix, As três ecologias, Campinas, Papirus, 1990, pg 25

xxii SANTOS, Milton - Metamorfoses do Espaço Habitado, Editora Hucitec, SP, 1996, 4ํo edição, pg 89

xxiii SERRES, Michel - O contrato Natural, Instituto Piaget, Lisboa, 1990, pg 37.

xxiv SERRES, Michel - O contrato Natural, Instituto Piaget, Lisboa, 1990, pg 58

xxv SANTOS, Milton - Metamorfoses do Espaço Habitado, Editora Hucitec, SP, 1996, 4ํe edição, pg 89

xxvi FOUCAULT, Michel. De outros espaços, Conferência proferida no Cercle d'Études Architecturales, em 14 de Março de 1967, publicado em Diacritics; 16-1, Primavera de 1986

xxvii SALWA, Mateus em https://www.academia.edu/10328182/The_Garden_as_a_Performance

xxviii SALWA, Mateus em https://www.academia.edu/10328182/The_Garden_as_a_Performance

xxix SALWA, Mateus em https://www.academia.edu/10328182/The_Garden_as_a_Performance

xxx Esse trecho é retirado do texto, de minha autoria, da narração do filme Um jardim em Floresta.
}

Recebido em: 14/11/2018

Aprovado em: 17/11/2018 